\title{
An Antibiotic Complex from Lysobacter enzymogenes Strain C3: Antimicrobial Activity and Role in Plant Disease Control
}

\author{
S. Li, C. C. Jochum, F. Yu, K. Zaleta-Rivera, L. Du, S. D. Harris, and G. Y. Yuen
}

First, second, sixth, and seventh authors: Department of Plant Pathology, University of Nebraska, Lincoln 68583; third, fourth, and fifth authors: Department of Chemistry, University of Nebraska, Lincoln 68583; and sixth author: Plant Science Initiative, University of Nebraska, Lincoln 68583.

Current address of first author: Department of Biology, Texas A\&M University, College Station 77843.

Current address of third author: Aureogen Biosciences, Inc., Kalamazoo, MI 49008.

Accepted for publication 19 February 2008.

\begin{abstract}
Li, S., Jochum, C. C., Yu, F., Zaleta-Rivera, K., Du, L., Harris, S. D., and Yuen, G. Y. 2008. An antibiotic complex from Lysobacter enzymogenes strain C3: Antimicrobial activity and role in plant disease control. Phytopathology 98:695-701.

Lysobacter enzymogenes $\mathrm{C} 3$ is a bacterial biological control agent that exhibits antagonism against multiple fungal pathogens. Its antifungal activity was attributed in part to lytic enzymes. In this study, a heat-stable antifungal factor (HSAF), an antibiotic complex consisting of dihydromaltophilin and structurally related macrocyclic lactams, was found to be responsible for antagonism by $\mathrm{C} 3$ against fungi and oomycetes in culture. HSAF in purified form exhibited inhibitory activity against a wide range of fungal and oomycetes species in vitro, inhibiting spore germination, and disrupting hyphal polarity in sensitive fungi. When applied to tall

the control. Although application of HSAF at $12.5 \mu \mathrm{g} / \mathrm{ml}$ did not reduce the incidence of conidial germination, it inhibited appressorium formation and suppressed Bipolaris leaf spot development. Two mutant strains of C3 (K19 and $\triangle$ NRPS) that were disrupted in different domains in the hybrid polyketide synthase-nonribosomal peptide synthetase gene for HSAF biosynthesis and had lost the ability to produce HSAF were compared with the wild-type strain for biological control efficacy against Bipolaris leaf spot on tall fescue and Fusarium head blight, caused by Fusarium graminearum, on wheat. Both mutant strains exhibited decreased capacity to reduce the incidence and severity of Bipolaris leaf spot compared with C3. In contrast, the mutant strains were as efficacious as the wild-type strain in reducing the severity of Fusarium head blight. Thus, HSAF appears to be a mechanism for biological control by strain C3 against some, but not all, plant pathogenic fungi.
\end{abstract} fescue leaves as a partially-purified extract, $\mathrm{HSAF}$ at $25 \mu \mathrm{g} / \mathrm{ml}$ and higher inhibited germination of conidia of Bipolaris sorokiniana compared with
Additional keywords: microbial fungicide, secondary metabolite.
The production of antibiotics, antimicrobial secondary metabolites, is an important mechanism of competition among microorganisms and plays an important role in many plant disease biological control systems $(5,10)$. Antibiotics produced by biological control agents, in native or modified form, can also be the basis for modern fungicides. For example, pyrrolnitrin, an antibiotic involved in biocontrol by Pseudomonas fluorescens strain Pf5 (13), was chemically modified into two commercial fungicides, fenpiclonil and fludioxonil, which are used as seed treatments against diverse fungal pathogens (20).

While Bacillus, Pseudomonas, and Streptomyces are the most widely studied genera of bacteria in regards to the production of antibiotics that may be useful against plant diseases, the potential importance of other bacterial genera in this role is beginning to be recognized. Lysobacter is a bacterial genus known to produce a number of antibiotics $(1,12,18,26,28,35)$. Myxin, first reported in L. antibioticus ATCC29479 (1,30), and xanthobaccins, produced by Lysobacter sp. SB-K88 (formerly reported as a strain of Stenotrophomonas sp. [11]) have antifungal activity and were implicated in biological control $(27,31)$. Multiple, unidentified antifungal compounds were thought to be involved in antagonism by L. enzymogenes strain 3.1T8 against Pythium aphanidermatum (4). Transposon mutagenesis of a putative polyketide synthase (PKS) gene in $3.1 \mathrm{~T} 8$ resulted in a loss of in vitro antagonism and

Corresponding author: G. Y. Yuen; E-mail address: gyuen1@unl.edu

doi:10.1094/PHYTO-98-6-0695

(C) 2008 The American Phytopathological Society reduced biocontrol activity (3). A heat-stable antifungal factor (HSAF) was isolated and characterized recently from $\mathrm{C} 3$, another biocontrol strain of L. enzymogenes (37). HSAF is a complex of at least three structurally-related compounds, the primary one being dihydromaltophilin, which was reported in a Streptomyces sp. (7) and is an analog of xanthobaccins. A hybrid PKS-nonribosomal peptide synthetase (NRPS) gene in C3 was shown to be responsible for biosynthesis of all of the HSAF compounds as mutants of $\mathrm{C} 3$ generated by disrupting specific domains in the PKS-NRPS gene no longer produced any of the HSAF associated compounds as identified by high-performance liquid chromatography (HPLC) and also lost in vitro antifungal activity (37). HSAF caused depolarized hyphal growth in Aspergillus nidulans, the effects being attributed to the disruption of sphingolipid biosynthesis in the fungus (25). Strain C3, which was reclassified from Stenotrophomonas maltophilia (33), is a biological control agent of multiple fungal and oomycetous pathogens $(6,17$, $21,22,38,39$ ), with field efficacy demonstrated most extensively against Bipolaris sorokiniana, causing Bipolaris leaf spot in turfgrasses, and Fusarium graminearum (Gibberella zeae teleomorph), causing Fusarium head blight in wheat. Lytic enzymes produced by $\mathrm{C} 3$, particularly chitinases and $\beta-1,3$-glucanases, have important roles in biological control of $B$. sorokiniana and $P$. ultimum $(29,40)$, while induced resistance also may be a mechanism for disease control by the strain (19). In these previous studies, none of the mechanisms alone could account for the total biological control capacity exhibited by C3. In one study (40), fractions from C3 culture fluid retained some antifungal activity after boiling despite chitinase activity being eliminated, 
and a low molecular weight fraction also exhibited antifungal activity. In another study (29), a mutant strain of C3 deficient in all $\beta$-1,3-glucanase activity was found to be unchanged in its ability to inhibit the oomycete P. ultimum on agar media compared with the wild type. These observations support secondary metabolites such as HSAF also being involved in antagonism of $\mathrm{C} 3$ against fungi and oomycetes.

Little is known as to the range of organisms that HSAF can inhibit, and the degree to which HSAF can affect plant infection by fungal pathogens. The role of HSAF in biological control of fungal pathogens by $\mathrm{C} 3$ also has not been established. The objectives of this study, therefore, were (i) to determine the spectrum of antimicrobial activity of HSAF and its effects on the morphology of fungal and oomycete pathogens; (ii) to determine the effects of HSAF on pre-penetration processes in B. sorokiniana on the phylloplane and the potential for the antibiotic to control foliar infection by this pathogen; and (iii) to ascertain whether HSAF might have a role in biological control of disease caused the fungi B. sorokiniana and $F$. graminearum.

\section{MATERIALS AND METHODS}

Microbial cultures. Strains of L. enzymogenes used in this study include $\mathrm{C} 3$, the wild-type (6); 5E4, a clp mutant of C3 inactive in antifungal antagonism and biological control (21); and HSAF-nonproducing mutants K19 and $\triangle$ NRPS disrupted in the ketosynthase domain of the PKS module and the condensation domain of the NRPS module, respectively, of the PKS-NRPS gene responsible for HSAF biosynthesis (37). Other microorganisms used in this study are listed in Table 1. Unless specified otherwise, all microorganisms were cultured routinely on onetenth-strength tryptic soy agar (10\% TSA; Sigma-Aldrich, St. Louis, MO) and cultures were incubated at $28^{\circ} \mathrm{C}$. Strain C3 was grown in $10 \%$ tryptic soy broth (TSB; Sigma-Aldrich) at $28^{\circ} \mathrm{C}$ for 4 days with shaking at $180 \mathrm{rpm}$ to produce broth cultures for

TABLE 1. Antimicrobial spectrum of heat-stable antifungal factor (HSAF)

\begin{tabular}{|c|c|c|}
\hline \multirow[b]{2}{*}{ Organism ${ }^{y}$} & \multicolumn{2}{|c|}{ Inhibition zone (mm) } \\
\hline & $\begin{array}{c}\text { Heated } \\
\text { culture } \\
\text { fluid }\end{array}$ & $\begin{array}{c}\text { TLC }_{-} \\
\text {purified } \\
\text { HSAF }\end{array}$ \\
\hline \multicolumn{3}{|l|}{ Fungi } \\
\hline Aspergillus nidulans A28 & 18 & 16 \\
\hline Bipolaris sorokiniana & 20 & 16 \\
\hline Candida albicans $\mathrm{CHS} 1$ & 15 & 9 \\
\hline Cryptococcus neoformans & 22 & 17 \\
\hline Cercospora clavata & 14 & 10 \\
\hline Fusarium graminearum $\mathrm{PH} 1$ & 19 & 13 \\
\hline Neurospora crassa & 20 & 17 \\
\hline Pichia anomala & 15 & 12 \\
\hline Rhizoctonia solani AG1-IA & 25 & 17 \\
\hline Rhizopus stolonifer & 20 & 16 \\
\hline Sclerotinia sclerotiorum & 20 & 16 \\
\hline Saccharomyces cerevisiae JC482 & 14 & 0 \\
\hline \multicolumn{3}{|l|}{ Oomycetes } \\
\hline Pythium ultimum var. ultimum & 24 & 20 \\
\hline Phytophthora sojae & 25 & 20 \\
\hline \multicolumn{3}{|l|}{ Bacteria } \\
\hline Bacillus pumilus & 15 & 0 \\
\hline Clavibacter michiganensis subsp. nebraskensis & 12 & 0 \\
\hline Escherichia coli $\mathrm{DH} 5 \alpha$ & 0 & 0 \\
\hline Pectobacterium carotovorum subsp. carotovorum & 0 & 0 \\
\hline Pseudomonas syringae pv. tomato DC3000 & 0 & 0 \\
\hline Xanthomonas campestris pv. phaseoli & 0 & 0 \\
\hline
\end{tabular}

y $P$. syringae pv. tomato was provided by J. R. Alfano; $S$. cerevisiae by M. B. Dickman; $P$. sojae by L. Giesler; C. michiganensis subsp. nebraskensis, $P$. carotovorum subsp. carotovorum, and X. campestris pv. phaseoli by A. K. Vidaver. All other microorganisms were from the culture collections of the authors.

z $\mathrm{TLC}=$ thin-layer chromatography. extraction of HSAF. All L. enzymogenes strains were resistant to rifampicin via spontaneous mutation, and their populations in cultures, aqueous suspensions and on leaves were determined by dilution plating on $10 \%$ TSA amended with rifampicin and cycloheximide, both at $100 \mathrm{mg} / \mathrm{liter}$.

Extraction and purification of HSAF. The antibiotic complex was investigated in this study in three forms: (i) fluid from a broth culture of $\mathrm{C} 3$ after removal of cells by centrifugation and filter sterilization; (ii) partially purified form extracted from culture fluid using ammonium sulphate and methanol (25); and (iii) purified form derived by thin-layer chromatography (TLC). These materials are referred to as culture fluid, extract, and TLC-purified HSAF, respectively. Prior to use in experiments, culture fluid and extract were heated at $70^{\circ} \mathrm{C}$ for $30 \mathrm{~min}$ to inactivate lytic enzymes. TLC-purified HSAF was produced from the extract using preparative TLC plates made with TLC-Silica gel 60 GF 254 (Sigma-Aldrich). The plates were developed in chloroform/ methanol (3:1). Separated fractions were visualized under UV light $(254 \mathrm{~nm})$ and recovered by methanol/acetate acid (99:1). The sole fraction with antifungal activity (Rf value of 0.39 ) was considered to contain HSAF (24).

Assays for antifungal activity. A plate inhibition assay was used in determining antimicrobial activity of heated C3 culture fluid and TLC-purified HSAF across a range of plant pathogenic and saprotrophic microorganisms, some in the latter group also being potential human pathogens (Table 1). In tests with filamentous fungi and oomycetes, a 6-mm-diameter mycelial plug taken from the margin of an actively growing culture on $10 \%$ TSA was transferred to the center of a fresh plate of the medium. In assays involving yeast or bacteria, test plates were inoculated with the organism by spreading $40 \mu \mathrm{l}$ of cell suspension $\left(\mathrm{OD}_{600}=0.5\right)$ on the agar surface. To apply C3 culture fluid, wells $(5 \mathrm{~mm}$ diameter) were cut into the agar at the perimeter of each plate and a $40-\mu l$ aliquot of culture fluid, or sterile $10 \%$ TSB used as the negative control, was added to each well. TLC-purified HSAF was tested by applying $20 \mu \mathrm{l}$ of sample (dissolved in methanol) onto filter paper disks $(5 \mathrm{~mm})$, allowing the methanol to evaporate off, and then placing the disks on the agar surface at the periphery of plates. Filter paper disks loaded with the same volume of methanol were used as controls. Each HSAF sample was tested in two replicate wells or filter paper disks against each organism. Cultures were incubated at $28^{\circ} \mathrm{C}$ for 1 to 4 days, depending upon the organism, prior to the size of growth inhibition zones surrounding the wells and disks being measured.

A spore germination assay was used for microscopic examination of the effects of HSAF on spore germination and hyphal development in fungi (B. sorokiniana isolate NE1 and $F$. graminearum isolate PH1) and the oomycete $P$. ultimum var. ultimum (here after referred to as P. ultimum) isolate P201. Conidia of the fungi were generated by growing the isolates on 10\% TSA for 10 days. Sporangia of $P$. ultimum, which germinate only into hyphae (36), were generated by growing isolate P201 on plates of $10 \%$ TSA flooded with sterile distilled water for 3 days. Conidia or sporangia were harvested and suspended in sterile distilled water (100 $\mathrm{ml}$ for each plate). Mycelium was removed by filtering the suspensions through 4 layers of sterile cheese cloth. The conidia or sporangia were collected by centrifugation at 2,000 rpm for $1 \mathrm{~min}$ and resuspended in 10\% TSB. Various volumes of TLC-purified HSAF dissolved in methanol were applied on slides and the methanol removed by evaporation at room temperature. Then, $5 \mu \mathrm{l}$ of spore suspension was applied to the same location as the HSAF sample, and the antibiotic was allowed to dissolve in the liquid. Final concentrations of HSAF were 20 and $40 \mu \mathrm{g} / \mathrm{ml}$. The slides were put in 15 -cm-diameter petri dishes lined with moist filter paper and incubated at $28^{\circ} \mathrm{C}$ for $3 \mathrm{~h}$ for $P$. ultimum, or $12 \mathrm{~h}$ for $F$. graminearum and B. sorokiniana. Spore germination and hyphal growth were observed under a Zeiss compound microscope at magnification $\times 100$ to $\times 400$. 
Evaluation of HSAF for Bipolaris leaf spot control. The effects of HSAF on epiphytic growth and infection of tall fescue by $B$. sorokiniana isolate NE1 was investigated in a growth chamber experiment under conditions previously described (39) using 45-day-old tall fescue (Festuca arundinacea Schreb. 'Kentucky-31') turf in 10-cm diameter pots. Partially purified HSAF extract was diluted to $12.5,25$, and $50 \mu \mathrm{g} / \mathrm{ml}$ with distilled water amended with the surfactant Induce $(0.01 \%$; Bayer Crop Science, Kansas City, MO), and then each dilution and a distilled water control was sprayed onto four pots of turf (20 ml per pot). One day after treatment application, turf foliage was inoculated with the pathogen $B$. sorokiniana by spraying suspensions of conidia $\left(1 \times 10^{5}\right.$ conidia $\left./ \mathrm{ml}\right)$ in water amended with Induce. Misting was provided for the first $36 \mathrm{~h}$ after pathogen inoculation to stimulate pathogen germination and growth. Leaves were collected $12 \mathrm{~h}$ after pathogen inoculation and stained with lactophenol acid fuchsin for microscopic examination of conidial germination, hyphal growth, and appressorium formation on leaf surfaces. More than 130 germlings for each treatment were examined. Pots of inoculated turf were incubated for 8 days for disease development. Disease severity (percent infected leaf area) was visually assessed in at least 10 leaves per pot. The experiment was conducted twice, the data being pooled for analysis of variance (ANOVA) and means separation using PROC MIXED (SAS Institute Inc., Cary, NC).

Evaluation of mutants deficient in HSAF production. HSAF-nonproducing mutant strains K19 and $\triangle$ NRPS were compared with wild-type $\mathrm{C} 3$ for antagonism against $B$. sorokiniana, $P$. ultimum, the yeast Saccharomyces cerevisiae, and the grampositive bacterium Clavibacter michiganensis subsp. nebraskensis in plate inhibition tests. In addition, the strains were evaluated for chitinase, $\beta$-1,3-glucanase, protease, lipases activities on media containing colloidal chitin, laminarin, skim milk, and Tween 80, respectively (21), and for biosurfactant activity (22). Colony morphology of each strain was examined on $10 \%$ TSA with the aid of a dissecting microscope.

Strains K19 and $\triangle$ NRPS were evaluated for biological control activity against $B$. sorokiniana in a series of five experiments. The first three experiments were conducted prior to the generation of strain $\triangle$ NRPS, and thus involved only strain K19 in comparison with wild-type strain C3 and the clp mutant strain 5E4. Strain $\triangle$ NRPS and wild-type C3 were tested in the last two experiments. The fourth experiment also involved mutant strain K19. Distilled water was used as the negative control in all experiments. Each bacterial strain was applied as a suspension of twice-washed cells $\left(10^{8} \mathrm{CFU} / \mathrm{ml}\right)$ from a 2-day-old culture on $1 / 10 \mathrm{TSA}$ sprayed onto four pots of turf. The treated turf was incubated overnight in the growth chamber prior to inoculation with pathogen conidia. Foliage in two pots of tall fescue treated with a bacterial strain was sampled immediately after treatment, and 1 day and 7 days after treatment. The samples were assayed for populations of the applied strain by dilution plating (39). Inoculated turf was rated for severity of leaf spot at the end of 8 days incubation as described previously. In addition, the number of lesions on sampled leaves was counted and the length of leaves was measured to determined incidence of infection, i.e., number of lesions per $10 \mathrm{~cm}$ of leaf blade. Data from each experiment was analyzed separately by ANOVA, and means separation was performed using the Fisher's least significant difference (LSD) test.

The mutant strains were compared with wild-type C3 in a series of four experiments for control of Fusarium head blight in wheat. Strain K19 was tested in all four experiments, while $\triangle$ NRPS was tested in one. Methods described previously (17) were used in evaluating the efficacy of the bacterial strains. Essentially, cell suspensions of C3 and the mutant strains, prepared as mentioned, and a sterile distilled water control were applied to flowering heads of 'Bobwhite' hard red spring wheat by spraying the heads to run-off. There were five or six replicate pots per treatment, each pot containing four plants with a total of five to seven flowering heads. Flowering heads were sampled immediately after bacterial treatment and just prior to pathogen inoculation for assay of the bacterial populations. Pots were placed in a moisture chamber overnight after bacterial treatment, and then the heads were sprayed with suspensions containing $5 \times 10^{5}$ conidia per $\mathrm{ml}$ of $F$. graminearum. The pots were incubated for another $48 \mathrm{~h}$ in the moisture chamber and then placed on a greenhouse bench. Sixteen to eighteen days after pathogen inoculation, the percent of diseased spikelets on each inoculated head was determined. Results for all heads in a pot were averaged prior to statistical analysis by ANOVA. Statistical analysis also was performed on arcsine-transformed data, but because the results were the same, only results using nontransformed data are reported. Each experiment was analyzed separately because treatments and numbers of replications differed among the experiments.

\section{RESULTS}

Antimicrobial activity of HSAF. Heated C3 culture fluid retained inhibitory activity against a wide range of fungi and oomycetes (Table 1). It was also inhibitory to gram-positive bacterial species but not gram-negative species. TLC-purified HSAF had a more restricted spectrum of activity compared to the heated culture fluid, lacking activity against Saccharomyces cerevisiae and all bacteria (Table 1).

The effects of HSAF on different stages of fungal growth were concentration dependent (Fig. 1). At higher concentration (40 $\mu \mathrm{g} / \mathrm{ml})$, TLC-purified HSAF inhibited spore germination in $B$. sorokiniana, F. graminearum, and $P$. ultimum. Although HSAF at the lower concentration $(20 \mu \mathrm{g} / \mathrm{ml})$ did not affect spore germination, it suppressed hyphal elongation and induced excessive branching in B. sorokiniana and $F$. graminearum. This same concentration slowed hyphal growth in $P$. ultimum compared with the control, but otherwise had no effect on hyphal morphology.

Effects of HSAF on infection of tall fescue by $B$. sorokiniana. HSAF extract applied at different concentrations to tall fescue leaves had different effects on germination and growth of $B$. sorokiniana. Although the frequency of germination at the lowest concentration $(12.5 \mu \mathrm{g} / \mathrm{ml})$ of HSAF extract was not affected compared with the distilled water control, the treatment caused excessive hyphal branching (Fig. 2B). There was also a significant reduction in appressorium formation accompanying the effects on hyphal branching. On control leaves, $72 \%$ of germlings developed at least one appressorium (Fig. 2A). However, only $22 \%$ of germlings on leaves treated with $12.5 \mu \mathrm{g} / \mathrm{ml}$ of HSAF extract developed appressoria. Higher concentrations of the extract $(25$ and $50 \mu \mathrm{g} / \mathrm{ml})$ inhibited conidial germination or hyphal elongation (Fig. 2C).

All concentrations of HSAF extract applied to tall fescue turf reduced the severity of Bipolaris leaf spot compared with the distilled water control (Fig. 3). Levels of disease inhibition conferred by the extract were dosage dependant. The treatment factor was highly significant $(P=0.0006)$. Similar results were obtained in the two experiments in which HSAF extract was tested for disease control efficacy, the experiment $\times$ treatment interaction being insignificant.

Antagonism and biocontrol activity of HSAF-deficient mutants. Mutant strains K19 and $\triangle$ NRPS retained lytic enzyme and biosurfactant activities of wild-type $\mathrm{C} 3$, but they also exhibited altered colony morphology, being paler and more mucoid, compared to C3 (Table 2). The mutant strains lost antagonism activity against $P$. ultimum, while retaining inhibitory activity against $S$. cerevisiae and $C$. michiganensis subsp. nebraskensis (Table 2; Fig. 4).

Biocontrol activity against Bipolaris leaf spot was found to be associated with the ability of $\mathrm{C} 3$ to produce HSAF (Table 3 ). In 
all experiments in which wild-type C3 and mutant strains were applied to tall fescue foliage, treatment with the wild-type strain resulted in significantly reduced levels of leaf spot incidence (lesions per centimeter of leaf) and disease severity (percent diseased leaf area) compared to treatment with the water control or the $c l p$-disrupted mutant 5E4. In comparison to wild-type C3, HSAF-minus strains K19 or $\triangle$ NPRS exhibited complete loss of ability or decreased ability to reduce disease incidence and severity. There was no significant difference in leaf spot incidence or disease between treatment with either K19 or $\triangle$ NPRS and treatment with the water controls or 5E4 in any of the experiments. In the one experiment involving both K19 and $\triangle$ NPRS, there was no difference in biocontrol activity between the two mutant strains. All of the bacterial strains in each experiment colonized foliage to similar levels, with population levels of the mutant strains being within $1 / 2 \log _{10}$ unit of the wild type (data not shown); from initial populations of 7.0 to $7.5 \log _{10} \mathrm{CFU} / \mathrm{g}$ leaf, numbers of applied bacteria typically increased by $1 \log _{10}$ unit over 8 days.

The ability of strain $\mathrm{C} 3$ to control Fusarium head blight, on the other hand, was not dependent on HSAF production (Table 4). In three out of the four experiments in which the HSAF-deficient mutant K19 was tested, K19 was equal to wild-type C3 in suppressing head blight development. In the remaining experiment, K19 exhibited an intermediate effect, with disease severity in the

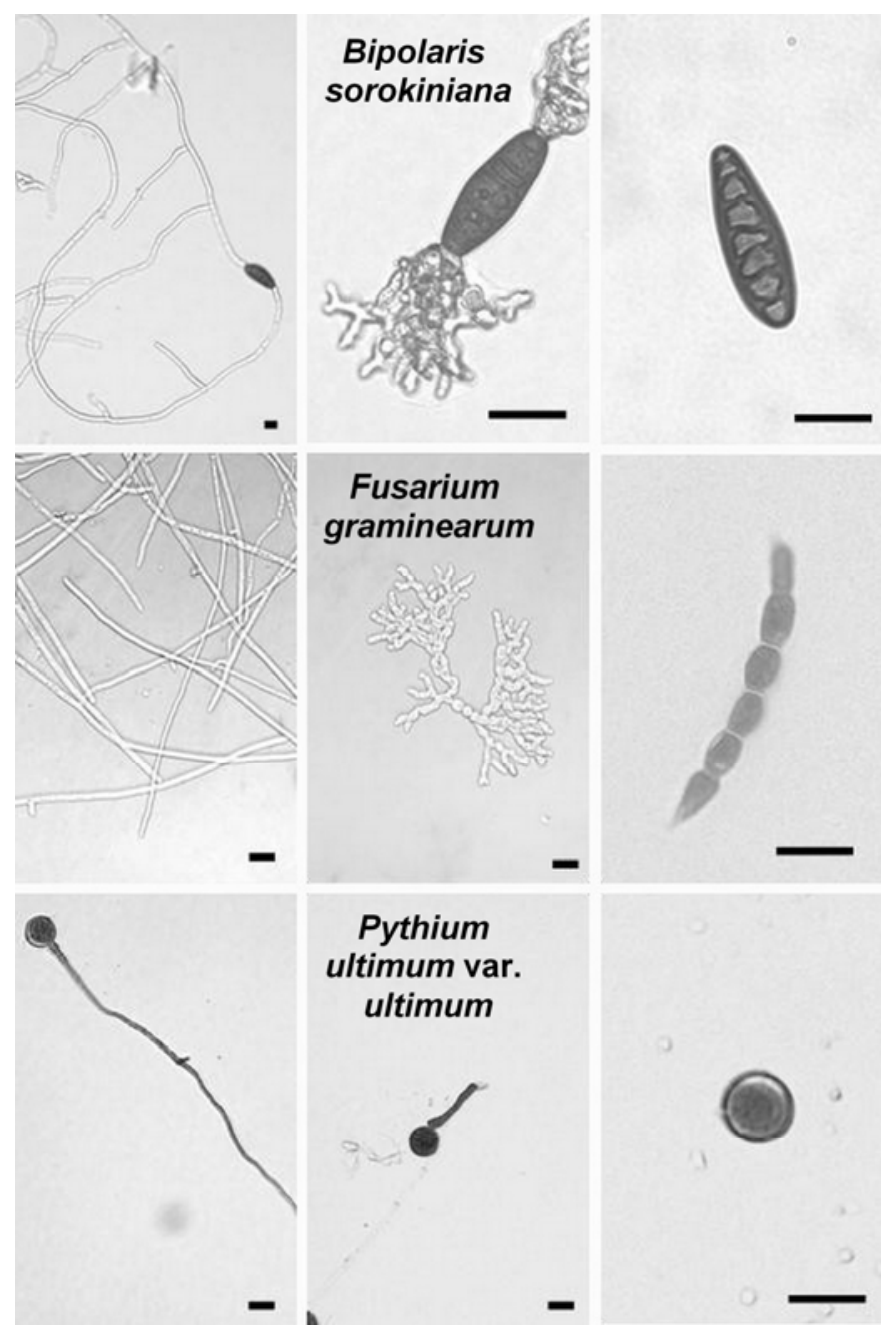

Fig. 1. Effects of thin-layer chromatography-purified heat-stable antifungal factor(HSAF) on spore germination and hyphal growth in Bipolaris sorokiniana, Fusarium graminearum, and Pythium ultimum var. ultimum. HSAF concentrations were 0,20 , and $40 \mu \mathrm{g} / \mathrm{ml}$ in the left, center, and right panels, respectively. Bars indicate $30 \mu \mathrm{m}$.
K19 treatment being statistically similar to that of C3 and the water control. In the one experiment in which $\triangle$ NPRS was evaluated, this mutant strain also was effective as wild-type C3 in controlling head blight. In all of the experiments, bacterial population levels on treated wheat heads were similar among the strains, with less than $1 \log _{10}$ unit difference between strains being found in any given sampling (data not shown). Populations on wheat heads typically were around $10^{7} \mathrm{CFU} / \mathrm{g}$ immediately after bacterial treatment, declining by approximately $1 \log _{10}$ unit 1 day later when the heads were inoculated with the pathogen.

\section{DISCUSSION}

The primary compound having HSAF activity has a chemical structure and molecular weight identical to dihydromaltophilin (37), a polyketide antibiotic containing both a macrocyclic lactam structural unit and a tetramic acid residue (7). This would place HSAF in a family of antibiotics that includes maltophilin produced by Stenotrophomonas maltophilia (16) and Streptomyces sp. (7), ikarugamycin from Streptomyces phaeochromogenes (15), xanthobaccins from Lysobacter sp. SB-K88 (11), alteramide A from Alteromonas sp. (32), and discodermide from the marine sponge Discodermia dissoluta (8). The sensitivity of a wide range of filamentous fungi and oomycetes and lack of sensitivity in bacteria and some yeasts to HSAF in this study is consistent with
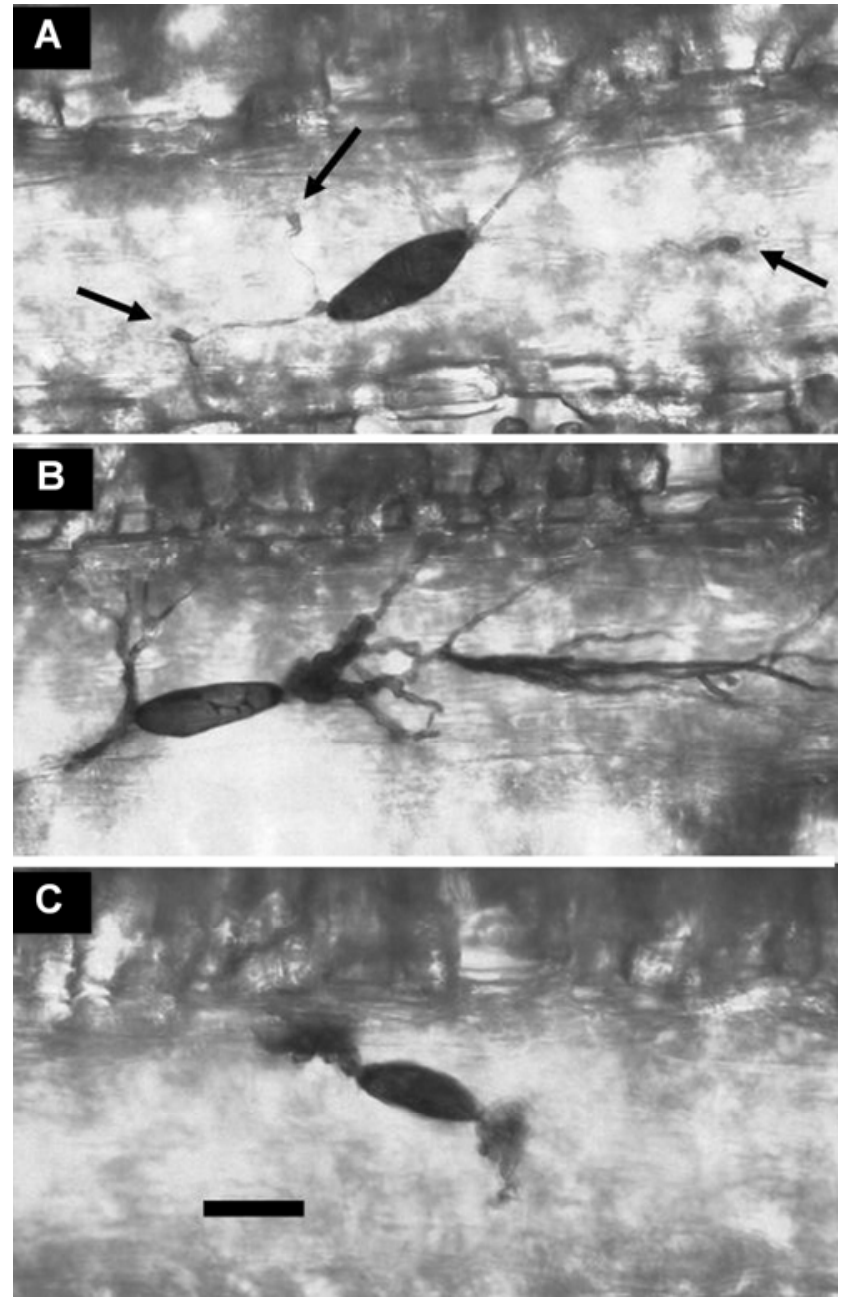

Fig. 2. Bipolaris sorokiniana hyphal growth and appressorium formation on the surface of tall fescue leaves treated with A, distilled water, $\mathbf{B}, 12.5 \mu \mathrm{g} / \mathrm{ml}$ heat-stable antifungal factor (HSAF) extract, and $\mathbf{C}, 50 \mu \mathrm{g} / \mathrm{ml} \mathrm{HSAF}$ extract. Arrows in panel A point to appressoria. Specimens were stained with lactophenol acid fuchsin $12 \mathrm{~h}$ after inoculation of leaves with pathogen conidia. Bar indicates $30 \mu \mathrm{m}$. 
the spectrum of activity reported for maltophilin and xanthobaccins $(16,27)$. The multiple unidentified antifungal compounds presumed to be produced by of L. enzymogenes 3.1T8 (4) might also include an antibiotic in this group, as the partial sequence for a PKS gene in 3.1T8 (3) was used to find the homologous gene for HSAF biosynthesis in strain C3 (37).

HSAF appears to be the primary factor responsible for antagonism by $\mathrm{C} 3$ against filamentous fungi and oomycetes in plate tests. This is consistent with the finding that loss of $\beta 1,3-$ glucanase activity in $\mathrm{C} 3$ did not affect antagonism against $P$. ultimum (29). HSAF, however, is not the sole heat-stable antimicrobial component produced in vitro by $\mathrm{C} 3$ because unknown heat-stable factors with antimicrobial activity against $S$. cerevisiae and bacteria also were found in the culture fluid. Whether a single compound is responsible for activity against bacteria and $S$. cerevisiae has not been determined. Myxin, a phenazine antibiotic produced by strains of $L$. antibioticus, is a candidate for such a compound as it is heat stable and has activity against bacteria and $S$. cerevisiae (30); it has not, however, been reported to be produced by L. enzymogenes.

HSAF causes inhibition of hyphal elongation and disruption of hyphal polarity in filamentous plant pathogenic true fungi, which is consistent with observations of HSAF effects on the model saprophytic fungus Aspergillus nidulans (25). While similar morphological effects were observed with the related antibiotic xanthobaccin A on the oomycete Aphanomyces cochliodes (14), we did not find HSAF to alter branching morphology in the oomycete $P$. ultimum. This would suggest that HSAF and xan-

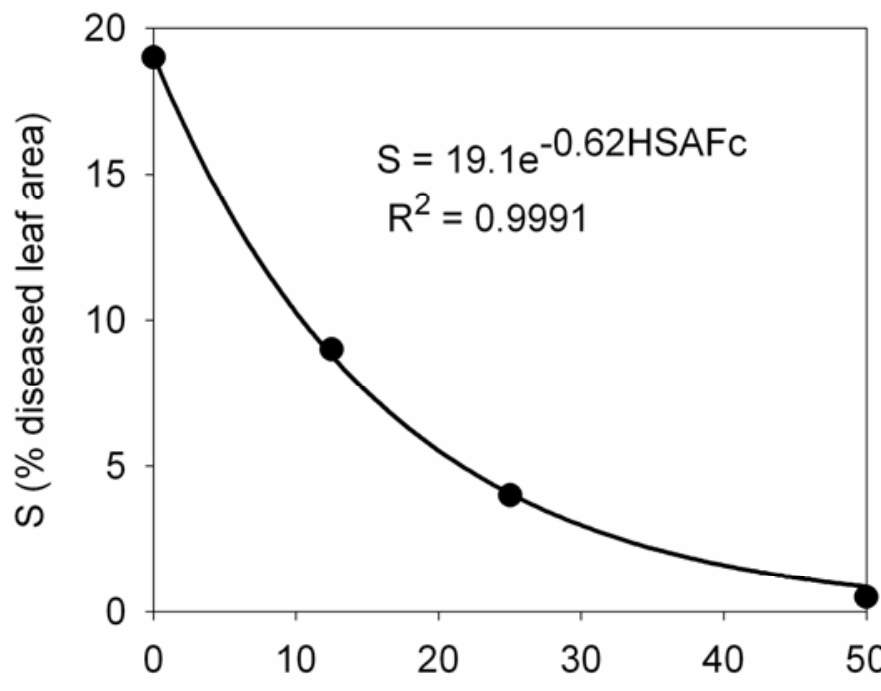

$\operatorname{HSAFc}(\mu \mathrm{g} / \mathrm{ml})$

Fig. 3. Suppression of Bipolaris leaf spot on tall fescue by various concentrations of heat-stable antifungal factor extract (HSAFc). Disease severity (S) was measured 8 days after inoculation of turf with conidia of Bipolaris sorokiniana. Results are means from two experiments, each with four replicates. thobaccins have different effects on oomycetes or that P. ultimum is unique in its response to HSAF.

HSAF also exhibited antifungal activity when applied to tall fescue foliage. Because of the difficulty in preparing sufficient amounts of TLC- or HPLC-purified material for the experiments, partially-purified extract was used instead. It can be assumed that the observed effects using the extract were due solely to HSAF because HPLC analyses of the extract and TLC-purified HSAF revealed a similar compliment of peaks associated with HSAF activity $(24,37)$. These peaks were responsible for all activity against filamentous fungi as the peaks and antifungal activity were absent from extracts prepared from HSAF-deficient mutants (37). On the leaf surface, HSAF at lower concentrations disrupted appressorium formation, and thus, while being fungistatic rather than fungicidal, it is nevertheless effective in suppressing foliar
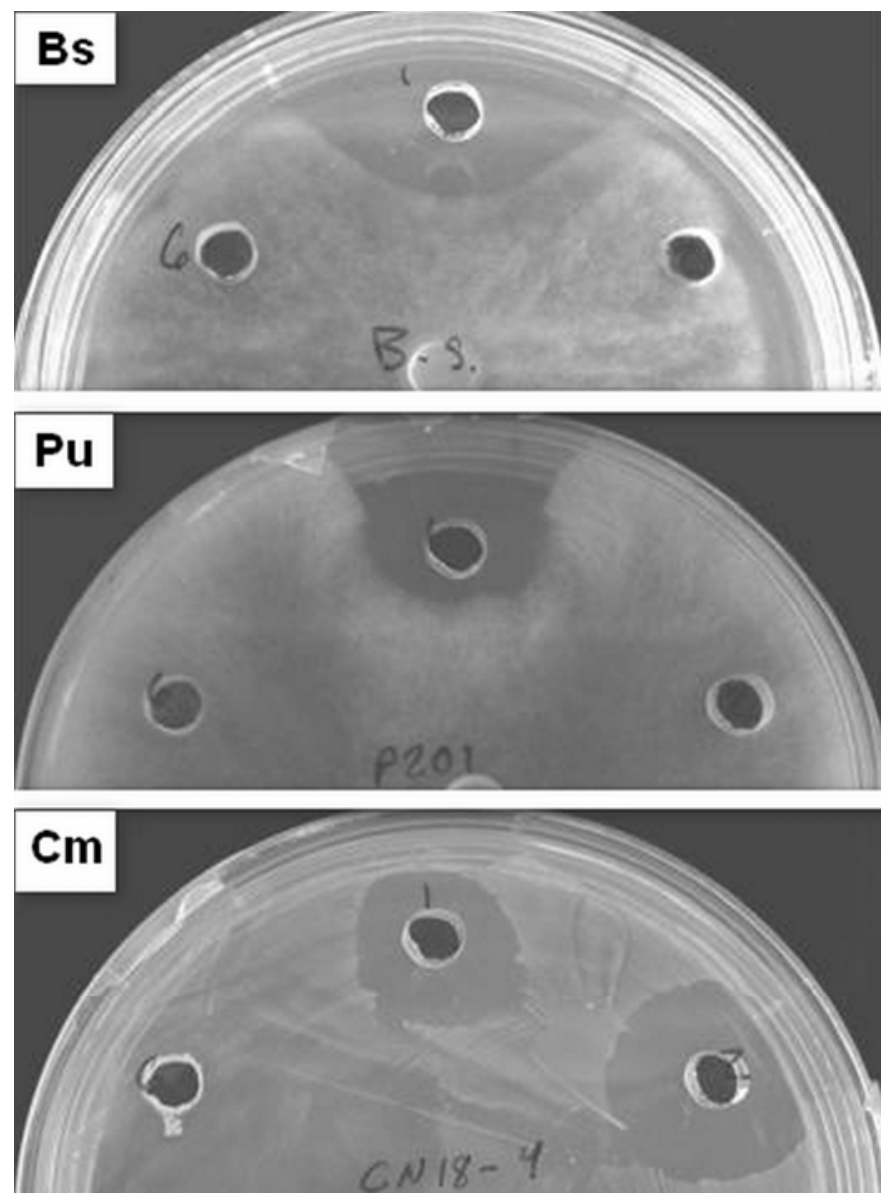

Fig. 4. Comparison of cell-free fluid from $10 \%$ tryptic soy broth cultures of Lysobacter enzymogenes $\mathrm{C} 3$ and heat-stable antifungal factor-deficient mutant strain K19 for inhibition of growth by Bipolaris sorokiniana (Bs), Pythium ultimum var. ultimum $(\mathrm{Pu})$, and Clavibacter michiganensis pv. nebraskensis $(\mathrm{Cm})$ on $10 \%$ tryptic soy agar. In each panel, wells contained (left to right) sterile broth, C3 culture fluid, or K19 culture fluid.

TABLE 2. Phenotype of wild-type Lysobacter enzymogenes C3 and heat-stable antifungal factor (HSAF)-nonproducing mutant strains K19 and $\triangle$ NRPS

\begin{tabular}{|c|c|c|c|c|c|c|c|c|c|c|}
\hline \multirow[b]{2}{*}{ Strain } & \multirow[b]{2}{*}{ Colony morphology } & \multicolumn{4}{|c|}{ Lytic activity $^{\mathrm{x}}$} & \multirow[b]{2}{*}{ Biosurfactant activity ${ }^{z}$} & \multicolumn{4}{|c|}{ In vitro growth inhibition ${ }^{y}$} \\
\hline & & Chi & Glu & Pro & Lip & & Bs & $\mathrm{Pu}$ & $\mathrm{Sc}$ & $\mathrm{Cm}$ \\
\hline $\mathrm{C} 3$ & Pale yellow, convex & + & + & + & + & + & + & + & + & + \\
\hline K19 & Cream-colored, mucoid & + & + & + & + & + & - & - & + & + \\
\hline$\triangle N R P S$ & Cream-colored, mucoid & + & + & + & + & + & - & - & + & + \\
\hline
\end{tabular}

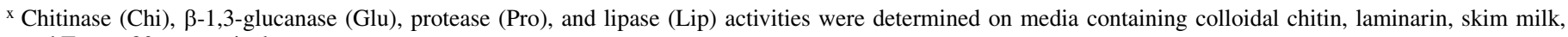
and Tween 80 , respectively.

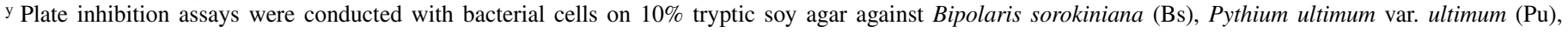
Saccharomyces cerevisiae (Sc), and Clavibacter michiganensis subsp. nebraskensis $(\mathrm{Cm})$.

${ }^{z}$ Biosurfactant activity was based on spreading of culture fluid droplets on polystyrene compared with sterile $10 \%$ trypticase soy broth. 


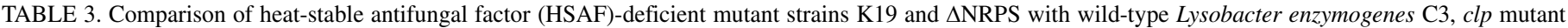
$5 \mathrm{E} 4$, and water control in five experiments for effects on incidence and severity of Bipolaris leaf spot on tall fescue

\begin{tabular}{|c|c|c|c|c|c|c|c|c|c|c|}
\hline \multirow[b]{2}{*}{ Treatment } & \multicolumn{5}{|c|}{ Incidence (lesions/cm leaf) ${ }^{x}$} & \multicolumn{5}{|c|}{ Severity $(\% \text { diseased leaf area })^{\mathrm{x}}$} \\
\hline & Expt 1 & Expt 2 & Expt 3 & Expt 4 & Expt 5 & Expt 1 & Expt 2 & Expt 3 & Expt 4 & Expt 5 \\
\hline $\mathrm{C} 3$ & $10.2 \mathrm{~B}^{\mathrm{y}}$ & $3.0 \mathrm{~B}$ & 4.1 B & $5.9 \mathrm{~B}$ & $2.7 \mathrm{~B}$ & $8.9 \mathrm{~B}$ & $2.0 \mathrm{~B}$ & $1.8 \mathrm{~B}$ & $8.5 \mathrm{~B}$ & $3.2 \mathrm{C}$ \\
\hline K19 & $11.6 \mathrm{~B}$ & $4.1 \mathrm{AB}$ & $5.2 \mathrm{AB}$ & - & $5.1 \mathrm{~A}$ & $19.8 \mathrm{AB}$ & $7.0 \mathrm{~A}$ & $6.2 \mathrm{~A}$ & - & $8.4 \mathrm{~B}$ \\
\hline$\triangle N R P S$ & $-{ }^{z}$ & - & - & $9.9 \mathrm{~A}$ & $4.6 \mathrm{~A}$ & - & - & - & $18.5 \mathrm{AB}$ & $9.1 \mathrm{~B}$ \\
\hline $5 \mathrm{E} 4$ & $15.5 \mathrm{~A}$ & $5.5 \mathrm{~A}$ & $6.9 \mathrm{~A}$ & - & - & $27.2 \mathrm{~A}$ & $7.6 \mathrm{~A}$ & $6.5 \mathrm{~A}$ & - & - \\
\hline Water & $15.2 \mathrm{~A}$ & $5.4 \mathrm{~A}$ & $6.1 \mathrm{~A}$ & $9.8 \mathrm{~A}$ & $5.7 \mathrm{~A}$ & $29.4 \mathrm{~A}$ & $8.6 \mathrm{~A}$ & $7.2 \mathrm{~A}$ & $22.0 \mathrm{~A}$ & $20.5 \mathrm{~A}$ \\
\hline$P$ & 0.005 & 0.054 & 0.036 & 0.031 & 0.002 & 0.053 & 0.034 & 0.019 & 0.020 & $<0.001$ \\
\hline $\mathrm{LSD}_{0.05}$ & 3.0 & 2.0 & 1.8 & 3.1 & 1.2 & 15.3 & 4.5 & 4.0 & 13.5 & 4.6 \\
\hline
\end{tabular}

$\mathrm{N}=4$ in all experiments.

y Values in a column followed by the same letter are not significantly different according to Fisher's least significant difference (LSD) test $(\alpha=0.05)$.

$\mathrm{z}-=$ not tested.

TABLE 4. Comparison of heat-stable antifungal factor (HSAF)-deficient mutant strains K19 and $\triangle$ NRPS with wild-type Lysobacter enzymogenes C3 and water control in four experiments for effects on the severity of Fusarium head blight in wheat

\begin{tabular}{lcccc}
\hline & \multicolumn{4}{c}{ Disease severity $\left(\%\right.$ diseased spikelets) $^{\mathrm{x}}$} \\
\cline { 2 - 5 } Treatment & Expt 1 & Expt 2 & Expt 3 & Expt 4 \\
\hline C3 & $8.7 \mathrm{~B}^{\mathrm{y}}$ & $10.6 \mathrm{~B}$ & $35.6 \mathrm{~B}$ & $5.1 \mathrm{~B}$ \\
K19 & $22.8 \mathrm{~B}$ & $24.1 \mathrm{AB}$ & $29.9 \mathrm{~B}$ & $3.0 \mathrm{~B}$ \\
$\Delta$ NRPS & $-\mathrm{z}$ & - & - & $11.2 \mathrm{~B}$ \\
Water & $57.5 \mathrm{~A}$ & $36.2 \mathrm{~A}$ & $71.3 \mathrm{~A}$ & $27.0 \mathrm{~A}$ \\
$P$ & 0.010 & 0.033 & $<0.001$ & $<0.001$ \\
LSD $_{0.05}$ & 27.0 & 18.5 & 18.4 & 9.6 \\
\hline
\end{tabular}

${ }^{x} \mathrm{~N}=6$ in experiments 1 and $2 ; \mathrm{N}=5$ in experiments 3 and 4 .

y Values in a column followed by the same letter are not significantly different according to Fisher's least significant difference (LSD) test $(\alpha=0.05)$.

$\mathrm{z}-=$ not tested.

infection by a fungal pathogen. Maintenance of hyphal polarity in Colletotrichum gloeosporioides was reported to be related to appressorium formation (9), and thus it is plausible that the target of HSAF regulates both biological processes. Natural productderived fungicides with activity against specific fungal infection stages have been suggested as future tools for fungal disease control (34), and appressorium formation has been suggested as such a target (2). Dihydromaltophilin was effective in suppressing grape downy mildew caused by Plasmopara viticola when applied to grape foliage (7). Similarly, xanthobaccin A applied to sugar beet seed suppressed damping-off disease caused by Pythium spp. (27). The effects of these antibiotics on diseases caused by true fungi, however, had not been reported. With its unique mode of action (25), and its effectiveness in appressorium formation on the phylloplane and suppressing disease development shown in this study, HSAF may be a model for a new generation of fungicides.

In a study on Lysobacter sp. SB-K88 (27), one piece of evidence offered for xanthobaccins being involved in biological control by SB-K88 was the observation that spontaneous mutants exhibited reduced xanthobaccin production also were reduced in biocontrol activity. The mutants, however, were not checked for pleotrophic effects. In our experience with C3, such spontaneous mutants can be readily found, but loss of antibiotic production in these mutants is associated with loss of lytic enzyme activity as well, most likely because the mutations occur in regulatory genes, such as clp, which globally controls expression of antagonism traits in C3 (22). Through mutant strains K19 and $\triangle$ NRPS, which were disrupted specifically in the PKS-NRPS gene, we provide more definitive evidence that production of HSAF is a mechanism in the biological control of some fungal pathogens.

While we have not attempted to detect HSAF on the foliage of C3-treated plants, results with the HSAF-deficient mutants K19 and $\triangle$ NRPS suggest that the bacterium produces HSAF on the phylloplane of tall fescue in sufficient quantity to affect infection by $B$. sorokiniana. While HSAF appears to be a key mechanism in reducing the severity (symptomatic leaf area) of Bipolaris leaf spot, the antibiotic has a lesser role in suppressing leaf spot incidence (lesions per leaf length), as evidenced by the HSAFdeficient mutant K19 exhibiting only partially diminished ability to reduce infection incidence. The number of lesions on a leaf is dictated primarily by the success rate of prepenetration processes, i.e., spore germination and appressorium formation, whereas symptomatic leaf area is also determined by the degree to which the pathogen grows through the mesophyll and produces toxins (23). We surmise that $B$. sorokiniana is particularly sensitive during the prepenetration phase to any one of the multiple mechanisms of antagonism elaborated by $\mathrm{C} 3$. Thus, lytic enzymes excreted by C3 $(29,40)$ or host resistance activated by C3 (19) may be sufficient to inhibit infection in the absence of HSAF. Inhibition of fungal metabolism and growth within leaf tissues, on the other hand, likely requires the full complement of mechanisms possible in $\mathrm{C} 3$, and thus, loss of HSAF production represents loss of an important component of a biocontrol system. This explanation is also consistent with the previous finding that loss in $\mathrm{C} 3$ of $\beta-1-3$-glucanase activity specifically also resulted in greatly reduced capacity of $\mathrm{C} 3$ to suppress the severity of disease caused by B. sorokiniana (29).

HSAF is not an important mechanism of biological control in all fungal disease situations as shown by the HSAF-minus mutants being unchanged from the wild-type $\mathrm{C} 3$ in their ability to control Fusarium head blight. These results, however, were not associated with low sensitivity of $F$. graminearum to HSAF, as purified HSAF was very active against the fungus in vitro. It is possible that HSAF was not produced by $\mathrm{C} 3$ on the surface of wheat heads and that biological control of $F$. graminearum by $\mathrm{C} 3$ was due instead, to induced resistance, as surmised in a previous study (17).

In conclusion, we demonstrated HSAF has the potential to arrest fungal growth and infection stages on the phylloplane and, consequently, suppress disease development. We also showed the importance of HSAF as a mechanism of biological control of certain fungal pathogens by $\mathrm{C} 3$. These findings, coupled with the previous discoveries of the unique mode of action of HSAF (25) and the genes for HSAF biosynthesis (37), point to the potentials of using $\mathrm{C} 3$ as a model for understanding the biosynthesis and activity of an entire family of antibiotics, and ultimately using them as the basis for developing new fungicides and identifying new strains of biocontrol agents.

\section{ACKNOWLEDGMENTS}

We thank S. Schoneweis for text editing and J. Alfano, M. Dickman, L. Geisler, and A. Vidaver for providing microbial strains. We also thank two anonymous reviewers for their insightful criticisms. This research was supported in part by a grant from the Nebraska Research Initiative and was a part of Multistate Project W-1147, Managing Plant Microbe Interactions in Soil to Promote Sustainable Agriculture. 


\section{LITERATURE CITED}

1. Christensen, P., and Cook, F. D. 1978. Lysobacter, a new genus of nonfruiting gliding bacteria with high base ratio. Int. J. Syst. Bacteriol. 28:367-393

2. Eckhard, T., Frank, E., Olov, S., and Heidrun, A. 1998. Inhibitors of appressorium formation in Magnaporthe grisea: A new approach to control rice blast disease. Pestic. Sci. 54:314-316.

3. Folman, L. B. 2003. Biological control of Pythium aphanidermatum in soilless systems - selection of biocontrol agents and modes of action. Ph.D. thesis. University of Leiden, Leiden, The Netherlands.

4. Folman, L. B., DeKlein, M. J. E. M., Postma, J., and van Veen, J. A. 2004. Production of antifungal compounds by Lysobacter enzymogenes isolate $3.1 \mathrm{~T} 8$ under different conditions in relation to its efficacy as a biocontrol agent of Pythium aphanidermatum in cucumber. Biol. Control 31:145154.

5. Fravel, D. R. 1988. Role of antibiosis in the biocontrol of plant disease. Annu. Rev. Phytopathol. 26:75-91.

6. Giesler, L. J., and Yuen, G. Y. 1998. Evaluation of Stenotrophomonas maltophilia strain C3 for biocontrol of brown patch disease. Crop Prot. 17:509-513.

7. Graupner, P. R., Thornburgh, S., Mathieson, J. T., Chapin, E. L., Kemmitt, G. M., Brown, J. M., and Snipes, C. E. 1997. Dihydromaltophilin: A novel fungicidal tetramic acid containing metabolite from Streptomyces sp. J. Antibiot. 50:1014-1019.

8. Gunasekera, S. P., Gunasekera, M., and McCarthy, P. 1991. A new bioactive macrocyline lactam from the marine sponge Discodermia dissolute. J. Org. Chem. 56:4830-4833.

9. Ha, Y. S., Memmott, S. D., and Dickman, M. B. 2003. Functional analysis of Ras in Colletotrichum trifolii. FEMS Microbiol. Lett. 226:315-321.

10. Handelsman, J., and Stabb, E. V. 1996. Biocontrol of soilborne plant pathogens. Plant Cell 8:1855-1869.

11. Hashidoko, Y., Nakayama, T., Homma Y., and Tahara, S. 1999. Structure elucidation of xanthobaccin A, a new antibiotic produced from Stenotrophomonas sp. strain SB-K88. Tetrahedron Lett. 40:2957-2960.

12. Hashizume, H., Hirosawa, S., Sawa, R., Muraoka, Y., Ikeda, D., Naganawa, H., and Igarashi, M. 2004. Tripropeptins, novel antimicrobial agents produced by Lysobacter sp. II. Structure elucidation. J. Antibiot. 57:52-58.

13. Howell, C. R., and Stipanovic, R. D. 1979. Control of Rhizoctonia solani on cotton seedlings with Pseudomonas fluorescens and with an antibiotic produced by the bacterium. Phytopathology 69:480-482.

14. Islam, M. T., Hashidoko, Y., Deora, A., Ito, T., and Tahara, S. 2005. Suppression of damping-off disease in host plants by the rhizoplane bacterium Lysobacter sp. strain SB-K88 is linked to plant colonization and antibiosis against soilborne peronosporomycetes. Appl. Environ. Microbiol. 71:3786-3796.

15. Ito, S., and Hirata, Y. 1977. The structure of ikarugamycin, an acyltetramic acid antibiotic possessing a unique as-hydrindacene skeleton. B. Chem. Soc. Jpn. 50:1813-1820.

16. Jakobi, M., Winkelmann, G., Kaiser, D., Kempler, C., Jung. G., Berg, G., and Bahl, H. 1996. Maltophilin: A new antifungal compound produced by Stenotrophomonas maltophilia R3089. J. Antibiot. 49:1101-1104.

17. Jochum, C. C., Osborne, L. E., and Yuen, G. Y. 2006. Fusarium head blight biological control with Lysobacter enzymogenes strain C3. Biol. Control 39:336-344.

18. Kato, A., Nakaya, S., Kokubo, N., Ohashi, Y., Hirata, H., Fuji, K., and Harada, K. 1998. A new anti-MRSA antibiotic complex, WAP-8294A. I. Taxonomy, isolation and biological activities. J. Antibiot. 51:929-935.

19. Kilic-Ekici, O., and Yuen, G. Y. 2003. Induced resistance as a mechanism of biological control by Lysobacter enzymogenes strain C3. Phytopathology 93:1103-1110.

20. Knight, S. C., Anthony, V. M., Brady, A. M., Greenland, A. J., Heaney, S. P., Murray, D. C., Powell, K. A., Schulz, M. A., Spinks, C. A., Worthington, P. A., and Youle, D. 1997. Rationale and perspectives on the development of fungicides. Annu. Rev. Phytopathol. 35:349-372.

21. Kobayashi, D. Y., Reedy, R. M., Palumbo, J. D., and Yuen, G. Y. 2005. A clp gene homologue belonging to the Crp gene family globally regulates lytic enzyme production, antimicrobial activity, and biological control activity by Lysobacter enzymogenes strain C3. Appl. Environ. Microbiol.
71:261-269.

22. Kobayashi, D. Y. and Yuen, G. Y. 2005. The role of $c l p$-regulated factors in antagonism against Magnaporthe poae and biological control of summer patch disease of Kentucky bluegrass by Lysobacter enzymogenes strain C3. Can. J. Microbiol. 51:719-723.

23. Kumar, J., Schäfer, P., Hückelhoven, R., Langen, G., Baltruschat, H., Stein, E., Nagarajan, S., and Kogel, K.-H. 2002. Bipolaris sorokiniana, a cereal pathogen of global concern: Cytological and molecular approaches towards better control. Mol. Plant Pathol. 3:185-195.

24. Li, S. 2005. An antifungal secondary metabolite produced by Lysobacter enzymogenes strain C3: Isolation, biological activity, mode of action and potential use in plant disease control. Ph.D. thesis. University of Nebraska, Lincoln.

25. Li, S., Du, L., Yuen, G., and Harris, S. D. 2006. Distinct ceramide synthases regulate polarized growth in the filamentous fungus Aspergillus nidulans. Mol. Biol. Cell 17:1218-1227.

26. Meyers, E., Cooper, R., Dean, L., Johnson, J. H., Slusarchyk, D. S., Trejo, W. H., and Singh, P. D. 1985. Catacandins, novel anticandidal antibiotics of bacterial origin. J. Antibiot. 38:1642-1648.

27. Nakayama, T., Homma, Y., Hashidoko, Y., Mizutani, J., and Tahara, S. 1999. Possible role of xanthobaccins produced by Stenotrophomonas sp. strain SB-K88 in suppression of sugar beet damping-off disease. Appl. Environ. Microbiol. 65:4334-4339.

28. O’Sullivan, J., McCullough, J. E., Tymiak, A. A., Kirsch, D. R., Trejo, W. H., and Principe, P. A. 1988. Lysobactin, a novel antibacterial agent produced by Lysobacter sp. I. Taxonomy, isolation and partial characterization. J. Antibiot. 41:1740-1744.

29. Palumbo, J. D., Yuen, G. Y., Jochum, C. C, Tatum, K., and Kobayashi, D. Y. 2005. Mutagenesis of $\beta$-1,3-glucanase genes in Lysobacter enzymogenes strain $\mathrm{C} 3$ results in reduced biological control activity towards Bipolaris leaf spot of tall fescue and Pythium damping-off of sugarbeet. Phytopathology 95:701-707.

30. Peterson, E. A., Gillespie, D. C., and Cook, F. D. 1966. A wide-spectrum antibiotic produced by a species of Sporangium. Can. J. Microbiol. 12:221-230.

31. Rondon, M. R., Borlee, B. R., Brady, S. F., Gross, J. A., Guenthner, B. J., Manske, B., Raffel, S. F., Weisz, J. B., Vincelli, P., Clardy, J., Goodman, R. M., and Handelsman, J. 1999. Biocontrol and root colonization by the gliding bacterium Lysobacter antibioticus. (Abstr.) Phytopathology 89(suppl.):S66.

32. Shigemori, H., Bae, M., Yazawa, K., Saski, T., and Kobayashi, J. 1992. Alteramide A, A new tetracyclic alkaloid from a bacterium Alteromonas sp. associated with the marine sponge Halichondria okadai. J. Org. Chem. 57:4317-4320.

33. Sullivan, R. F., Holtman, M. A., Zylstra, G. J., White, J. F., Jr., and Kobayashi, D. Y. 2003. Taxonomic positioning of two biological control agents for plant diseases as Lysobacter enzymogenes based on phylogenetic analysis of $16 \mathrm{~S}$ rDNA, fatty acid composition and phenotypic characteristics. J. Appl. Microbiol. 94:1079-1086.

34. Thines, E., Anke, H., and Weber, R. W. 2004. Fungal secondary metabolites as inhibitors of infection-related morphogenesis in phytopathogenic fungi. Mycol. Res. 108:14-25.

35. Tsubotani, S., Hida, T., Kasahara, F., Wada, Y., and Harada, S. 1984. Cephabacins, new cephem antibiotics of bacterial origin. III. Structural determination. J. Antibiot. 37:1546-54.

36. van der Plaats-Niterink, A. J. 1981. Monograph of the genus Pythium. Stud. Mycol. 21.

37. Yu, F., Zaleta-Rivera, K., Zhu, X., Huffman, J., Millet, J. C., Harris, S. D., Yuen, G., Li, X. C., and Du, L. 2007. Structure and biosynthesis of heatstable antifungal factor (HSAF), a broad-spectrum antimycotic with a novel mode of action. Antimicrobiol. Agents Chemother. 51:64-72.

38. Yuen, G. Y., Steadman, J. R., Lindgren, D. T., Schaff, D., and Jochum, C. 2001. Bean rust biological control using bacterial agents. Crop Prot. 20:395-402.

39. Zhang, Z., and Yuen, G. Y. 1999. Biological control of Bipolaris sorokiniana on tall fescue by Stenotrophomonas maltophilia C3. Phytopathology 89:817-822.

40. Zhang, Z., and Yuen, G. Y. 2000. The role of chitinase production by Stenotrophomonas maltophilia strain C3 in biological control of Bipolaris sorokiniana. Phytopathology 90:384-389. 